\title{
Keefektifan Penggunaan Modul Sistem Gerak pada Manusia Berbasis Inkuiri Interactive Demonstration untuk Memberdayakan Keterampilan Berpikir Analitis Siswa
}

\author{
Fakhrurrazi $^{1}$, Sajidan $^{1}$, Puguh Karyanto ${ }^{1}$ \\ ${ }^{1}$ Pendidikan Sains-Universitas Sebelas Maret
}

\begin{tabular}{l}
\hline INFO ARTIKEL \\
\hline Riwayat Artikel: \\
Diterima: $20-02-2019$ \\
Disetujui: $19-04-2019$
\end{tabular}

\section{Kata kunci:}

inquiry module; interactive demonstration; analytical thinking skills; modul inkuiri; interactive demonstration; keterampilan berpikir analitis

\author{
Alamat Korespondensi: \\ Fakhrurrazi \\ Pendidikan Sains \\ Universitas Sebelas Maret \\ Jalan Ir. Sutami No.36 A, Pucangsawit, Kec. Jebres, Kota Surakarta \\ E-mail: fakhrurrazi291@gmail.com
}

\begin{abstract}
The aims of this research is to know effectiveness motion system module in humans based on interactive demonstration inquiry in empowering analytical thinking skills. This research method is quantitative descriptive. Data analysis techniques using pretest-posttest control group design were then tested using independent sample t-test and n-gain test. The results of the research show interactive demonstration inquiry based module stated quite effective in empowering analytical thinking skills. It was shown that the average n-gain was $68.52 \%$ and the results of independent sample t-test showed that the value of Sig. (2-tailed) was $0.000<0.05$, meaning there are significant differences between cognitive learning outcomes of students in the experimental and control class.
\end{abstract}

\begin{abstract}
Abstrak: Tujuan penelitian ini adalah mengetahui keefektifan modul sistem gerak pada manusia berbasis inkuiri interactive demonstration dalam memberdayakan keterampilan berpikir analitis. Metode penelitian ini adalah deskriptif kuantitatif. Teknik analisis data menggunakan pretest-posttest control group design kemudian diuji menggunakan independent sample t- test dan uji n-gain. Hasil penelitian menunjukkan modul berbasis inkuiri interactive demonstration dinyatakan cukup efektif memberdayakan keterampilan berpikir analitis. Ditunjukkan perolehan rerata $n$-gain (\%) sebesar $68,52 \%$ dan hasil uji independent sample t-test tersebut diketahui nilai Sig.(2-tailed) adalah sebesar $0.000<0,05$, artinya terdapat perbedaan yang signifikan antara hasil belajar kognitif peserta didik di kelas eksperimen dan kontrol.
\end{abstract}

Pembelajaran adalah kegiatan yang dilakukan oleh guru secara terprogram dalam desain instruksional yang menciptakan proses interaksi antara sesama peserta didik, guru dengan peserta didik dan dengan sumber belajar. Pembelajaran bertujuan untuk perubahan perilaku manusia dan ia mencakup segala sesuatu yang dipikirkan dan dikerjakan (Anni, 2007). Pembelajaran merupakan salah satu wujud kegiatan pendidikan di sekolah. Kegiatan pendidikan di sekolah berfungsi membantu pertumbuhan dan perkembangan anak agar tumbuh ke arah positif (Sugandi, 2007). Keberhasilan pencapaian tujuan pendidikan tergantung pada kualitas pelaksanaan proses belajar mengajar di sekolah. Oleh karena itu, sekolah sebagai lembaga pendidikan berkewajiban memberikan fasilitas pelayanan, kualitas pembelajaran, dan kesempatan belajar seluas-luasnya kepada siswa untuk mengembangkan potensi dirinya seoptimal mungkin agar tujuan pendidikan tersebut dapat tercapai. Pembelajaran yang berorientasi kepada siswa memiliki karakteristik melibatkan siswa secara aktif dalam pembelajaran (Ergül et al., 2011). Proses belajar mengajar pada hakikatnya adalah proses komunikasi, yaitu proses penyampaian pesan dari sumber pesan melalui saluran/media tertentu ke penerima pesan (Muhson, 2010). Sumber belajar yang digunakan dalam rangka mengembangkan potensi peserta didik harus diarahkan pada pemberdayaan keterampilan berpikir analitis. Menurut Marzano bahwa keterampilan berpikir analitis merupakan salah satu bagian dari keterampilan berpikir tingkat tinggi (Heong et al., 2013). Ada lima aspek proses kognitif dalam keterampilan berpikir analitis, yaitu penyesuaian, klasifikasi, analisis kesalahan, generalisasi, dan spesifikasi (Dubas \& Toledo, 2016). 
Berdasarkan temuan di lapangan pada observasi awal yang dilakukan di MA Negeri 2 Surakarta, proses pembelajaran belum mengarahkan pada pemberdayaan keterampilan berpikir tingkat tinggi, dimana salah satu bagian dari aspek berpikir tingkat tinggi marzano adalah keterampilan berpikir analitis. Berpikir analitis ditujukan dari hasil deskriptif dalam bentuk persentase hasil jawaban soal-soal keterampilan berpikir analitis versi Marzano dan Kendall (2007) dan pengkategorian yang diadaptasi dari (Karim \& Normaya, 2015) sebagai berikut (1) penyesuaian (matching): 51,3\% (kategori rendah), (2) klasifikasi (classifying): 46\% (kategori rendah), (3) analisis kesalahan (analyzing errors): 39,4\% (kategori sangat rendah), (4) generalisasi (generalizing): 47,6\% (kategori rendah) dan (5) spesifikasi (specifying): 30\% (kategori sangat rendah). Dan rata-rata dari lima indikator di atas hasil keterampilan berpikir analitis peserta didik MA Negeri 2 Surakarta adalah 43,8\% (kategori rendah) dari jumlah tiga puluh peserta didik yang ada. Hal ini mengindikasikan materi sistem gerak pada manusia yang diajarkan selama ini belum banyak mengarah pada tipe soal berpikir analitis.

Rendahnya nilai pada materi sistem gerak pada manusia didapat berdasarkan hasil analisis persentase penguasaan materi Biologi pada soal Ujian Nasional di MA Negeri 2 Surakarta Tahun Pelajaran 2016/2017 yang menunjukkan bahwa pada materi sistem gerak pada manusia tergolong masih rendah dan belum mencapai ketuntasan minimum. Skor penguasaan materi tahun 2016/2017 sebesar 47,62\% pada tingkat sekolah, 60,57\% pada tingkat kota, 52,53\% pada tingkat provinsi dan 48,00\% pada tingkat nasional (BSNP).

Usaha-usaha untuk memberdayakan keterampilan berpikir analitis, peserta didik dalam pembelajaran biologi dapat dilaksanakan dengan pemilihan bahan ajar yang tepat. Bahan ajar yang digunakan seharusnya sesuai dengan karakteristik materi yang akan diajarkan dan tujuan pembelajaran khusus (Anitah, 2009). Bahan ajar yang sering digunakan oleh peserta didik adalah buku paket dan modul dengan cakupan materi yang masih luas dan umum tanpa disesuaikan dengan karakteristik masing-masing materi yang akan dipelajari. Begitu juga modul, modul yang digunakan hanya berisikan materi dan latihan soal. Menurut (Russell, 1973), modul adalah bentuk bahan ajar yang disajikan secara mandiri, peserta didik dapat mengatur kecepatan dan intensitas belajarnya secara mandiri, dapat digunakan secara individual dan gabungan. Hal tersebut didukung oleh (Jablon \& Wilkinson, 2006), modul dirancang agar siswa terlibat aktif dalam kegiatan pembelajaran dari menganalisis permasalahan, merancang percobaan hingga mempresentasikannya. Keterlibatan siswa secara aktif dalam kegiatan pembelajaran adalah salah satu cara meningkatkan antusiasme yang mendorong tercapainya tujuan pembelajaran.

Penggunaan modul akan lebih bermakna jika diiringi dengan suatu pendekatan, supaya penggunaan modul lebih terarah dan jelas (Hernawan, Permasih, \& Dewi, 2007). Modul yang dikembangkan materi sistem gerak pada manusia berbasis inkuiri interactive demonstration. Berdasarkan hasil uji level inkuiri pada peserta didik kelas XI IPA 2 MA Negeri 2 Surakarta data yang didapatkan pada level inkuiri interactive demontration tergolong rendah, yakni sebesar 52,7\% (kategori kurang terampil). Hal ini menandakan bahwa level inkuiri terkhusus interactive demontration pada peserta didik kelas XI IPA masih rendah, artinya proses pembelajaran (model) yang diajarkan perlu melihat karakteristik intelektual peserta didik (Wenning, 2011). Modul berbasis inkuiri interactive demontration merupakan salah satu sumber belajar berupa sajian materi yang dilengkapi dengan pertanyaan-pertanyaan produktif beserta latihan keterampilan proses sains melalui penemuan, dilengkapi dengan soal untuk memberdayakan keterampilan berpikir analitis (Daryanto, 2013).

Menurut Ruche dan Jason (dalam Ikhsan, Sutarno, \& Prayitno, 2016) modul berbasis inkuiri berisikan kegiatan pembelajaran yang mendorong peserta didik untuk menganalisis, memecahkan permasalahan berdasarkan fakta-fakta yang ditemukan dan didesain untuk mendapatkan pemahaman konseptual. Modul biologi berbasis inkuiri interactive demonstration bertujuan agar peserta didik dapat belajar lebih mandiri sesuai dengan petunjuk-petunjuk yang ada. Modul berbasis inkuiri interactive demonstration yang diterapkan pada materi sistem gerak merupakan modul yang menekankan penemuan konsep melalui pemecahan masalah sehari-hari dengan sintaks: observasi, manipulasi, generalisasi, verifikasi, dan aplikasi(Wenning \& Khan, 2011). Tugas guru hanya sebagai motivator dan pembimbing peserta didik yang mengalami kesulitan agar peserta didik dapat terarah dalam proses menemukan konsep melalui pemecahan masalah.

Berdasarkan pemikiran tersebut, maka penulis merasa tertarik untuk mengadakan penelitian dengan judul "keefektifan penggunaan modul sistem gerak pada manusia berbasis inkuiri interactive demonstration untuk memberdayakan keterampilan berpikir analitis siswa MA". Tujuan dilakukannya penelitian ini adalah untuk mendiskripsikan keefektifan modul sistem gerak pada manusia berbasis inkuiri interactive demonstration untuk memberdayakan keterampilan berpikir analitis siswa MA.

\section{METODE}

Dalam penelitian ini, teknik analisis data yang digunakan adalah quasi experimental design, Desain ini mempunyai kelompok kontrol, tetapi tidak dapat berfungsi sepenuhnya untuk mengontrol variabel-variabel luar yang memengaruhi pelaksanaan eksperimen. Sedangkan pola desain yang digunakan adalah nonequivalent control group pretest-posttest (Sugiyono, 2012). Desain uji keefektifan pada penelitian ini menggunakan dua kelompok kelas yaitu kelas kontrol dan kelas eksperimen. Teknik analisis yang digunakan adalah pengujian komparatif dengan statistik paramentris berupa uji independent sample t- test dan uji normalized gain (Sugiyono, 2016). Analisis data tersebut dilakukan dengan mengunakan program analisis SPSS Statistics 17.0.

Independent Sample T Test (uji T) digunakan untuk menentukan apakah dua sampel yang tidak berhubungan memiliki rata-rata yang berbeda. Keluaran Independent Sample T Test (uji T) adalah berupa perbandingan ada tidaknya perbedaan ratarata posttest kelas eksperimen dengan rata-rata posttest kelas kontrol. Independent Sample T Test (uji T) didahului dengan uji 
prasyaratnya yaitu uji normalitas (syarat mutlak) dan homogenitas (syarat tidak mutlak). Uji normalitas yang menggunakan metode uji Shapiro-Wilk dilakukan untuk mengetahui apakah data sampel yang digunakan berasal dari populasi yang terdistribusi normal. Uji homogenitas yang diuji menggunakan metode uji Levene's dilakukan untuk mengetahui ada tidaknya perbedaan variansi antar kelompok. Besar taraf signifikasi yang digunakan adalah 0,05. Uji normalized gain dilakukan untuk mengetahui keefektifan penggunaan modul berbasis inkuiri interactive demonstration dalam memberdayakan keterampilan berpikir analitis peserta didik. Uji normalized gain dilakukan dalam penelitian menggunakan kelas eksperimen dan kelas kontrol. Uji normalized gain dilakukan untuk mengetahui keefektifan modul tersebut dengan membandingkan nilai pretest posttest kelas eksperinmen dan nilai pretest posttest kelas control (Stewart \& Stewart, 2010). Populasi dari penelitian ini adalah siswa kelas XI IPA MAN 2 Surakarta, sedangkan sampel pada penelitian ini siswa kelas XI IPA 3 dan XI IPA 4 MAN 2 Surakarta.

\section{HASIL}

Deskripsi data hasil belajar kognitif yang diperoleh dari kelas eksperimen dan kontrol serta nilai pretes dan postes, dapat dilihat pada tabel 1 dan gambar 1.

Tabel 1. Data Hasil Belajar Kognitif

\begin{tabular}{cccccc}
\hline Data Hasil Belajar Peserta didik & N & Min & Max & Mean & Std. Deviation \\
\hline Pretest Eksperimen & 30 & 23 & 63 & 46.22 & 9.499 \\
Posttest Eksperimen & 30 & 70 & 97 & 83.11 & 6.429 \\
Pretest Kontrol & 30 & 23 & 63 & 45.33 & 9.330 \\
Posttest Kontrol & 30 & 43 & 83 & 59.67 & 10.071 \\
\hline
\end{tabular}

Berdasarkan tabel 1 menunjukkan bahwa kelas kontrol memperoleh rata-rata pretest tidak jauh berbeda dibandingkan kelas eksperimen yaitu 45.33 dan 46.22 , hal ini menunjukkan bahwa masing-masing kelas baik kelas kontrol maupun kelas eksperimen memiliki kemampuan awal yang relatif sama. Setelah proses belajar mengajar dengan menggunakan modul berbasis inkuiri interactive demonstration pada kelas eksperimen, didapatkan nilai posttes kelas eksperimen lebih tinggi dibandingkan kelas kontrol yaitu 59.67 dan 83.11 .

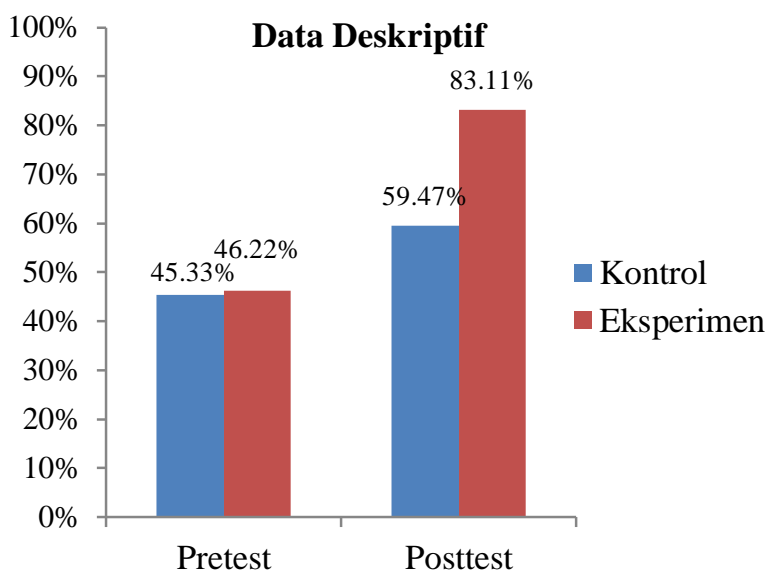

\section{Gambar 1. Histogram Data Deskriptif Kelas Eksperimen dan Kontrol}

Berdasarkan gambar 1 menunjukkan bahwa kelas XI IPA 4 (kelas eksperimen) memperoleh nilai rata-rata pretes dan postes yang lebih tinggi dibandingkan kelas XI IPA 3 (kelas kontrol). Begitu juga dengan deskripsi pada Tabel 1 dapat disimpulkan bahwa kelas yang menggunakan modul berbasis inkuiri interactive demonstration memperoleh rata-rata pretest dan posttest yang lebih tinggi dibandingkan kelas yang menggunakan modul atau buku paket sekolah. Kemudian, pada uji Independent Sample T Test, diperoleh hasil sebagaimana dapat dilihat pada tabel 2. 
Tabel 2. Hasil Uji Independen Sample t-test

\begin{tabular}{llll}
\hline \multicolumn{1}{c}{ Uji } & \multicolumn{1}{c}{ Jenis Uji } & \multicolumn{1}{c}{ Hasil } & \multicolumn{1}{c}{ Keputusan } \\
\hline Hasil & Independent & nilai Sig.(2-tailed) & Terdapat perbedaan yang signifikan (nyata) \\
Post & Sample t-test & $=.000<0,05$ & antara hasil belajar kelas yang menggunakan \\
test & & & modul berbasis inkuiri interactive \\
& & & $\begin{array}{l}\text { demonstration dengan kelas yang tidak } \\
\text { menggunakan modul berbasis inkuiri } \\
\end{array}$ \\
& & & interactive demonstration \\
\hline
\end{tabular}

Berdasarkan perhitungan pada tabel 2 diketahui nilai Sig.(2-tailed) adalah sebesar $0.000<0,05$, artinya terdapat perbedaan yang signifikan (nyata) antara hasil belajar kognitif peserta didik di kelas yang menggunakan modul inkuiri interactive demonstration (kelas eksperimen) dan yang tidak menggunakan modul inkuiri interactive demonstration (kelas kontrol). Pada uji Normalized Gain (N-Gain) hasil belajar, hasil analisis disajikan pada tabel 3 dan gambar 2.

Tabel 3. Hasil Uji Nilai Normalized Gain Keterampilan Berpikir Analitis

\begin{tabular}{clcc}
\hline Data Hasil Belajar & Kelas & $\boldsymbol{N}$-Gain Score (\%) & Keterangan \\
\hline \multirow{2}{*}{$N$-Gain } & Eksperimen & 68,52 & Cukup efektif \\
& Kontrol & 25,71 & Tidak efektif \\
\hline
\end{tabular}

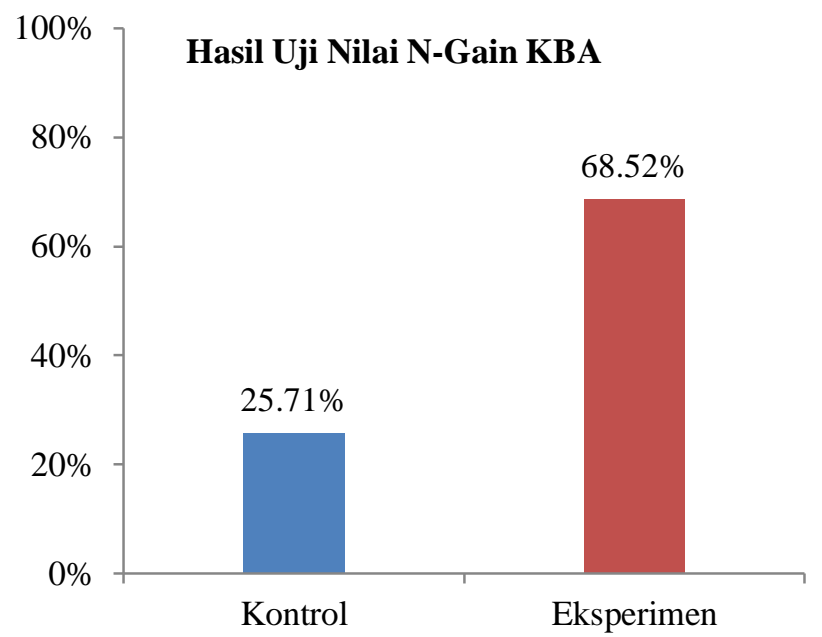

Gambar 2. Histogram Hasil Uji Nilai Normalized Gain KBA

Berdasarkan hasil perhitungan normalized gain sebagaimana ditampilkan pada tabel 3, diperoleh rata-rata kenaikan hasil belajar kelas eksperimen dari 30 orang peserta didik sebesar 68,52\% yang menurut kriteria Hake (1999) nilai tersebut menunjukkan bahwa kenaikan hasil belajar peserta didik dalam kategori cukup efektif. Sedangkan pada kelas kontrol diketahui data normalized gain sebesar $25,71 \%$ dengan kriteria peningkatan tidak efektif.

Berdasarkan hasil data perhitungan normalized gain keterampilan berpikir analitis seperti ditampilkan pada gambar 2, hasil belajar kelas eksperimen lebih tinggi nilainya $(68,52 \%)$ dibandingkan kelas kontrol (25,71\%). Dapat disimpulkan kelas dengan penggunaan modul berbasis inkuiri intractive demonstration lebih tinggi nilai hasil belajarnya dibandingkan kelas kontrol dengan menggunakan modul dan buku paket sekolah.

Modul berbasis inkuiri intractive demonstration pada materi sistem gerak pada manusia cukup efektif dalam memberdayakan keterampilan berpikir analitis peserta didik. Hasil uji coba lapangan operasional pada penelitian ini meliputi data keterampilan berpikir analitis peserta didik. Data keterampilan berpikir analitis peserta didik diperoleh dari pretest dan posttest, lalu dianalisis nilai normalized gain untuk mengetahui keefektifannya. Analisis peningkatan keterampilan berpikir analitis peserta didik dilakukan menggunakan kriteria Hake (1999). 


\section{PEMBAHASAN}

Uji keefektifan modul berbasis inkuiri interactive demonstration dalam memberdayakan keterampilan berpikir analitis peserta didik diawali dengan mengukur kemampuan awal peserta didik tentang materi sistem gerak pada manusia pada kelas eksperimen dan kelas kontrol melalui pretest. Hasil analisis terhadap nilai pretest keterampilan berpikir analitis (Tabel 1) diketahui bahwa tidak ada perbedaan yang signifikan antara kedua kelas, artinya kedua kelas memiliki kemampuan yang sama.

Setelah dilakukan pembelajaran dengan eksperimen yang berbeda pada kedua kelas, kemudian dilakukan pengukuran hasil belajar peserta didik melalui posttest. Hasil analisis terhadap nilai posttest keterampilan berpikir analitis (Tabel 1) menunjukkan bahwa rata-rata posttest kelas eksperimen lebih tinggi daripada kelas kontrol. Seperti yang dikemukakan oleh (Suastika, 2018) keefektifan modul diukur dari (1) penguasaan bahan ajar peserta didik, dan (2) respon peserta didik. Untuk mengetahui penguasaan bahan ajar peserta didik digunakan tes. Ali (2005) menyatakan bahwa pembelajaran menggunakan modul lebih efektif dibandingkan pembelajaran konvensional karena menggunakan modul peserta didik dapat belajar secara mandiri. Dengan demikian, peserta didik dapat mengembangkan langkah, kebutuhan, dan kemampuan dalam belajar yang berpengaruh pada hasil belajar peserta didik di kelas yang diterapkan pembelajaran menggunakan modul sebagai bahan ajar peserta didik.

Setelah diperoleh hasil analisis pretest dan posttest pada kedua kelas berdasarkan aspek keterampilan berpikir analitis, dilakukan analisis terhadap normalized gain untuk mengetahui perbedaan peningkatan hasil belajar peserta didik setelah diberikan pembelajaran dengan modul berbasis inkuiri interactive demonstration dan kelas kontrol. Berdasarkan hasil Independent Sample T Test (uji T) pada aspek berpikir analitis (Tabel 3) diperoleh hasil normalized gain kedua kelas berbeda secara signifikan. Rata-rata normalized gain kelas eksperimen yaitu sebesar 68,52\%, lebih tinggi daripada kelas kontrol yaitu sebesar $25,71 \%$. Besar nilai normalized gain kelas eksperimen termasuk dalam kriteria cukup efektif dan kelas kontrol termasuk kriteria tidak efektif menurut Hake (1999).

Modul berbasis inkuiri interactive demonstration lebih efektif dibandingkan modul sekolah dalam dalam meningkatkan keterampilan berpikir analitis peserta didik karena memiliki tujuan dan materi yang jelas, soal evaluasi yang valid dan kegiatan yang terarah berdasarkan indikator berpikir analitis yang difasilitasi melalui model pembelajaran inkuiri interactive demonstration. Pembelajaran inkuiri interactive demonstration memberikan pengaruh lebih baik dibandingkan pembelajaran konvensional karena pada pembelajaran inkuiri interactive demonstration peserta didik dituntut untuk berpikir tingkat tinggi dalam menyelesaikan masalah sesuai tahap-tahap dalam inkuiri interactive demonstration yang dilakukan secara berdiskusi dengan berbantuan modul sehingga peserta didik merasa senang dalam pembelajaran (Nikmah, dkk, 2016). Didukung dengan hasil penelitian Sever, dkk., (2013) yang menemukan bahwa pembelajaran yang berbasis inkuiri dan diintegrasikan metode demonstrasi selaras dengan teori kontruktivisme sehingga dapat mengoptimalkan hasil belajar peserta didik melalui proses pembelajaran yang lebih interaktif karena peserta didik dengan adanya kegiatan praktik menjamin peserta didik dapat berinteraksi dengan sekitarnya, meliputi objek dan fenomena yang lebih kuat dan bermakna dalam kehidupan sehari-hari individu serta pengalaman belajar dalam suasana mengajar dapat dicapai. Lebih lanjut, Brotherton, \& Abowd (2004) mengintegrasikan pembelajaran dengan metode demonstrasi dapat meningkatkan kualitas proses pembelajaran yang dilakukan oleh guru dan peserta didik menjadi lebih interaktif dan bermakna.

\section{SIMPULAN}

Berdasarkan hasil penelitian di atas maka dapat disimpulkan bahwa modul sistem gerak pada manusia berbasis inkuiri interactive demonstration cukup efektif dalam memberdayakan keterampilan berpikir analitis karena menunjukkan adanya perbedaan posttes normalized gain antara kelas kontrol yang menggunakan buku paket Biologi sekolah dengan kelas eksperimen yang menggunakan modul sistem gerak pada manusia berbasis inkuiri interactive demonstration.

Ada beberapa saran yang diberikan terkait dengan keefektifan penggunaan modul berbasis inkuiri interactive demonstration. Pertama, uji keefektifan modul sistem gerak pada manusia berbasis inkuiri interactive demonstration masih terbatas pada uji lapangan operasional yang hanya melibatkan satu sekolah sehingga perlu pengujian lebih luas (diseminasi) dengan sampel yang lebih luas. Kedua, uji keefektifan pada penggunaan modul guru berbasis inkuiri interactive demonstration pada materi sistem gerak pada manusia perlu dilakukan, seperti pada keefektifan penggunaan modul peserta didik.

\section{DAFTAR RUJUKAN}

Anitah, S. (2009). Teknologi Pembelajaran . Surakarta: Yuma Pustaka.

Anni, C. T. (2007). Psikologi Belajar. Semarang: UNNES Press.

BSNP. (2017). Laporan Hasil Ujian Nasional. Jakarta: Puslitbang Kemdikbud.

Brotherton, J. A., Abowd, G. D., Brotherton, J. A., \& Abowd, G. D. (2004). Lessons Learned From eClass: Assessing Automated Capture and Access in the Classroom. ACM Transactions on Computer-Human Interaction, 11(2), 121-155.

Dubas, J. M., \& Toledo, S. A. (2016). Taking Higher Order Thinking Seriously: Using Marzano's Taxonomy in the Economics Classroom. International Review of Economics Education, 21, 12-20. https://doi.org/10.1016/j.iree.2015.10.005 
Ergül, R., Şımşeklı, Y., Çaliş, S., Özdılek, Z., Göçmençelebı, Ş., \& Şanli, M. (2011). The Effects of Inquiry-Based Science Teaching on Elementary School Students' Science Process Skills and Science Attitudes. Bulgarian Journal of Science and Education Policy, 5(1), 48-68. https://doaj.org/article/ee50561dcf21492696b303a707a10a6f

Heong, Y. M., Othman, W. B., Yunos, J. B. M., Kiong, T. T., Hassan, R. Bin, \& Mohamad, M. M. B. (2013). The Level of Marzano Higher Order Thinking Skills among Technical Education Students. International Journal of Social Science and Humanity, 1(2), 121-125. https://doi.org/10.7763/ijssh.2011.v1.20

Hernawan, A. H., Permasih, \& Dewi, L. (2007). Panduan Pengembangan Bahan Ajar. In DIKTI Kemdiknas. http://file.upi.edu/Direktori/FIP/JUR._Kurikulum_dan_Tek._Pendidikan/194601291981012permasih/Pengembangan_Bah an_Ajar.pdf

Ikhsan, M., Sutarno, \& Prayitno, B. A. (2016). Materi Sistem Gerak Manusia untuk Meningkatkan Hasil Belajar Siswa Kelas XI MIA SMA Negeri 1 Wera. Jurnal Inkuiri, 5(1), 133-142.

Jablon, J. R., \& Wilkinson, M. (2006). Engagement Strategies to Facilitate. Young Children on the Web, (March), 1-5.

Karim, \& Normaya. (2015). Kemampuan Berpikir Kritis Siswa dalam Pembelajaran Matematika dengan Menggunakan Model Jucama di Sekolah Menengah Pertama. EDU-MAT Jurnal Pendidikan Matematika, 3(1), 92-104.

Muhson, A. (2010). Pengembangan Media Pembelajaran Berbasis Teknologi Informasi. Jurnal Pendidikan Akuntansi Indonesia, 8(2). https://doi.org/10.21831/jpai.v8i2.949

Nikmah dkk. (2016). Pengembangan Modul Biologi Inquiry Based on Interactive Demonstration untuk Memberdayakan Hasil Belajar Siswa Kelas XII IA pada Materi Bioteknologi di SMA Negeri 1 Magelang. Jurnal Inkuiri, 5(3), $104-112$.

Stewart, J., \& Stewart, G. (2010). Correcting the Normalized Gain for Guessing. The Physics Teacher, 48(3), $194-196$. https://doi.org/10.1119/1.3317458

Suastika, I. K. (2018). Pengembangan Modul Pembelajaran Bilangan Berbasis Tematik Saintifik. Jurnal Inspirasi Pendidikan, $8(1), 24-32$.

Sugiyono. (2012). Metode Penelitian Kuantitatif, Kualitatif dan R \& D. Bandung: Alfabeta.

Sugiyono. (2016). Metode Penelitian dan Pengembangan (Research and Development/R\&D). In Bandung: Alfabeta.

Wenning, C. J. (2011). The Levels of Inquiry Model of Science Teaching. Journal of Physics Teacher Education Online, 6(2), 9-16.

Wenning, C. J., \& Khan, M. A. (2011). Levels of Inquiry Model of Science Teaching : Learning sequences to lesson plans. Journal of Physics Teacher Education Online, 6(2), 17-20. 